\title{
Are Global Experiences During Medical School Associated with Future Medical Practice? A Cross- Sectional Analysis of Survey and Medical School Application Data
}

\section{Shay E Slifko ( $\sim$ shay_slifko@med.unc.edu )}

University of North Carolina at Chapel Hill https://orcid.org/0000-0002-1924-7703

Nadja A. Vielot

University of North Carolina at Chapel Hill Department of Family Medicine

\section{Sylvia Becker-Dreps}

University of North Carolina at Chapel Hill Department of Family Medicine

Donald E. Pathman

University of North Carolina at Chapel Hill Department of Family Medicine

Justin G. Myers

University of North Carolina at Chapel Hill Department of Emergency Medicine

Martha C. Carlough

University of North Carolina at Chapel Hill School of Medicine

\section{Research article}

Keywords: Medical Students, Global Health, Global Health Electives, Underserved, Medical Education, Career Choice

Posted Date: December 2nd, 2020

DOl: https://doi.org/10.21203/rs.3.rs-116751/v1

License: (c) (i) This work is licensed under a Creative Commons Attribution 4.0 International License. Read Full License 


\section{Abstract}

Background: Global health interest has grown among medical students over the past twenty years. Most medical schools offer global health opportunities. Studies suggest completing global health electives during medical school may increase likelihood of choosing a primary care discipline or working with underserved populations, yet they have generally not considered students' interests and experiences prior to medical school. This study aimed to assess the associations of pre-medical school factors and global electives in medical school on subsequently working in global health and with underserved populations in the United States (U.S.) and whether respondents reported perceived benefits from global electives.

Methods: We surveyed medical school graduates (classes of 2011-2015) from a large public medical school in the U.S. to describe current practice settings and previous global health experience. We evaluated work, volunteer, and educational experiences preceding medical school, socioeconomic status, race and ethnicity using American Medical College Application Service (AMCAS) data. We assessed the association between students' backgrounds, completing global health electives in medical school and current work in global health or with underserved populations in the U.S.

Results: Of 161 respondents, five to eight years post-graduation, 78\% reported work, research, or teaching with a focus on global or underserved U.S. populations. Completing a global health elective during medical school $(p=0.0002)$ or during residency $(p=0.01)$ were positively associated with currently working with underserved populations, and pre-medical school experiences were not associated $(p=0.1)$. Adjusting for race and ethnicity, completing a global health elective during medical school was associated with a $38 \%$ greater prevalence of working with an underserved population. Perceived benefits from global electives included improved cultural awareness, language skills, public health and research skills, and ability to practice in technology-limited settings.

Conclusion: Medical school graduates who participated in global electives as students were more likely than their peers to pursue careers with underserved populations in the U.S. They reported the experience improved their cultural competency and public health skills. These data can be used to design medical school curricula that encourage global health electives, and support skills that will benefit future work with underserved populations, either in the U.S. or abroad.

\section{Background}

Medical school experiences can play a formative role in student career decision making and can have substantial influence on future practice choices, both in terms of medical specialties pursued and populations served. These experiences may be realized through formal curricular components, clinical training sites, and elective opportunities, all of which can have a focus on underserved patient populations. Many underserved populations in the U.S. lack high-quality and accessible primary health care, increasing the likelihood of experiencing reduced life expectancy and poverty. Increasing the work 
force of primary care physicians in underserved areas is needed to meet the medical needs and improve quality of life of populations living in these areas (Mullen, F. et. al., 2010).

Opportunities for medical students to learn skills important for working with underserved populations include clinical training in rural and urban settings; language immersion programs; migrant farmworker outreach; refugee health initiatives; and short term global health experiences in low- and middle- income countries (LMICs) (Steeb, D. R.,Dascanio, S. A., \& Kiser, S. N., 2019; Mullan, F. C., 2010). Medical students and resident physicians develop stronger preferences for serving underserved populations as compared to their peers when they have engaged in global health experiences (Greer Jr., P. J., et. al., 2018; Jogerst K, Callender B, Adams V, et al., 2015; Law, I. R., \& Walters, L., 2015). Furthermore, students who attended a medical school with a strong social mission or grew up in a medically underserved setting are also more likely to work with the underserved (O'Connell, T. F. et. al., 2018). Prior studies have also identified variables including student loan debt burden and physicians' race and ethnicity as strong correlates of practice and intention to practice in underserved populations (Puddey, I.B., et.al., 2015).

In LMICs, patient populations face similar challenges to underserved populations in the United States: healthcare provider shortages, limited access to adequate healthcare services, low health literacy, long travel distances, and high financial burdens for families to obtain health care (Law, I. R., \& Walters, L., 2015). Global health electives during medical school may provide students the opportunity to learn from resourceful healthcare workers in often constrained systems; develop a deeper understanding of the barriers to healthcare, learn about public health systems in other countries, and contribute to research studies to address a high priority health problem in the population. Global health engagement has increased rapidly within both medical school and residency programs and the reported benefits include improved medical knowledge, procedural skills, increased recognition of cost-effective practices and improvement in cultural competence (Kasper, J., 2020; Lu, P. M. et al., 2018). Graduates self-report a greater understanding of the social determinants of health, intentions to practice in rural settings, and a commitment to care for the medically underserved (Litzelman, D. K. et al., 2017). Yet, more information is needed to understand how global medical education programs are associated with - and may contribute to - increasing numbers of graduated medical students who subsequently pursue work in underserved communities, including outside the U.S.

To this end, the study team surveyed graduates of a large public medical school to understand whether participating in global health electives as medical students or later as residents is associated with practice settings with underserved populations. The study team also evaluated other potential influences, including sociodemographic factors and experiences in global health and underserved populations prior to entering medical school. Finally, we summarized participants' perceptions of their global health experiences and the perceived benefits to their careers. These findings may be used by medical schools interested in adapting their curricula to most effectively produce graduates who are equipped to serve vulnerable populations.

\section{Methods}




\section{Study population}

Eligible study participants were 2011 through 2015 graduates from a large public medical school in a small city setting within the southeastern United States. The school had a traditional $2+2$ curriculum when these classes attended, with an option for an elective but no required global health experience.

\section{Data Sources}

The study team developed a self-administered, web-based questionnaire in the Qualtrics ${ }^{\text {TM }}$ survey platform. The study survey was created using a modified delphi process by faculty and staff within the Office of Global Health Education who are active in global health and medical student education. Building on prior research (Carlough M.C. et al., 2016), a retrospective questionnaire about global health learning experiences was piloted with among medical students and faculty interested and active in global health. The questionnaire solicited information on participants' current employment situation, location, and characteristics of the patient populations they currently serve. Participants were also asked about details of any global elective experiences during medical school, residency, motivations for participating, perceived benefits of the global health experience, and skills they believe they gained from the elective. The study team identified eligible alumni and email addresses from an opt-in alumni registry maintained by the school, and emailed study invitations to all eligible alumni with periodic email reminders to those who had not yet responded. A \$20 electronic café gift card was offered for participation. The survey opened May 7, 2019 and closed July 24, 2019.

To augment survey data, the study team accessed information provided by subjects to the American Medical College Application Services (AMCAS) when they had applied to medical schools. AMCAS data are maintained by the school for all of its students. The pre-medical school entry data consisted of demographics and information on work and volunteer experiences prior to applying to medical school, as well as major and minor areas of undergraduate study.

\section{Study variables}

Basic demographic, educational, medical training, and medical practice characteristics were collected from all survey participants. The principal exposure of interest was whether participants completed a global elective during medical school. From the AMCAS data, work and volunteer experiences prior to medical school were considered global in nature if they included a study abroad program; study or use of a foreign (i.e. not English) language; research, clinical work, or volunteerism in a global setting; or a medical mission. Experience was focused on a special population if it included interaction or research in individuals who were impoverished, homeless, victims of violence, or people living with HIV/AIDS. Undergraduate majors and minors were global in nature if they included study of a foreign language or global relations. To evaluate the association between these factors and subsequent career directions, we defined the principal outcome of interest as whether participants "worked with underserved populations" in their current work settings: 
1. Clinical practice with a population that is typically medically underserved, including in federal or state health professional shortage areas; Indian, tribal, or migrant health facilities; community health centers (including mental health); rural health centers; critical access hospitals; correctional facilities;

2. Clinical practice (e.g. with immigrant populations), research, teaching, or programmatic work with a global focus from the U.S.; or

3. Clinical practice in a global setting.

\section{Data Analysis}

The study team summarized participant characteristics with univariate frequencies and percentages. We used the Mantel-Haenszel chi-squared test to identify differences in the proportions of participants who experienced the outcome by participation in global electives and other variables of interest, including graduates' race and ethnicity, self-report of being socioeconomically disadvantaged, undergraduate areas of study, and work and volunteer experience prior to medical school.

After assessing bivariate associations, the study team ran a multivariable log-binomial model to estimate the relative prevalence of the outcome by the main exposure of interest- whether participants completed a global elective during medical school. We identified Black, Asian, Indigenous, or Latinx race and ethnicity as a potential confounder based on a review of the literature and analysis of a causal diagram (Garcia, A. N. et al., 2018). Finally, the study team summarized participants' perceptions of whether their global elective experiences affected their careers positively or negatively, using descriptive statistics and illustrative quotations. Qualitative responses were independently reviewed and categorized as reflecting a positive, negative, or neutral impression of the global health elective by two authors (SES, NAV) and compared them to resolve discrepancies.

Missing data for exposure and outcome variables were excluded from the analysis without imputation. All analyses were completed using SAS version 9.4 (Research Triangle Park, North Carolina). A p-value level of statistical significance was set at $a=0.05$. The study was approved by the Institutional Review Board of the University of North Carolina at Chapel Hill (\#18-2374).

\section{Results}

The study team identified 824 alumni who had graduated between 2011 and 2015. Thirty-two email addresses proved invalid, resulting in 792 presumed contacts with alumni. Of these, 172 alumni (21.7\%) responded to the survey, of whom 167 provided data on the outcome and were included in analyses; three participants who reported being unemployed were excluded. Based on data from AMCAS applications, most of the 167 eligible participants were women (59.9\%) and identified as White (77.8\%) and non-Latinx $(96.4 \%)$ and were ages $30-34$ years at the time of the survey (58.1\%) (Table 1$)$. Nearly all participants $(99.4 \%)$ spoke English as their native language, and $7.8 \%$ reported growing up socioeconomically disadvantaged. 
Table 1

Characteristics of study participants from medical school classes of 2011-2015 $(n=167)$

$\mathrm{N}(\%)$

Demographics

Female sex

Race (2 missing)

African American

$9(5.3)$

Asian

Native American

$1(0.6)$

White

130

(77.8)

Other

$1(0.6)$

More than one race

$1(0.6)$

Not reported

$11(6.4)$

Ethnicity (1 missing)

Not Latinx

Mexican American/Chicanx/Puerto Rican/Spanish/Latinx

$6(3.6)$

Age group (years)

$25-29$

$30-34$

$35-39$

$40+$

Applicant self-reports as socioeconomically disadvantaged (14 missing)

Applicant's native language is English (14 missing)

Experience prior to medical school

College major/minor global in nature

Pre-med school work or volunteer experience global in nature ${ }^{b}$ (14 missing) 
Pre-med school work or volunteer experience focused on special populations ${ }^{c}(14$ missing)

Details of current medical activities

Currently employed

Completed formal training relevant to global health

Masters in Public Health

Other masters or doctorate

Global health certificate

Current position

Resident

Fellow

Outpatient provider

Inpatient provider

Administrator

Other

Currently practicing outside of the United States

Working in non-metropolitan statistical area $<50,000$ population (16 missing)

Currently working in a practice serving special communities

No

Health professional shortage area

State designated shortage area

Federally designated health center

Not federally designated health center

Federal designation 


\begin{tabular}{|ll|}
\hline & $\mathbf{N}(\%)$ \\
\hline Federally qualified health center & $10(6.0)$ \\
\hline Indian Health Services & $1(0.6)$ \\
\hline Rural health clinic & $1(0.6)$ \\
\hline Critical access hospital & $2(1.2)$ \\
\hline Academic practice & \\
\hline Community health center & 85 \\
\hline Tribal/urban Indian clinic & $(50.9)$ \\
\hline Health department & $4(2.4)$ \\
\hline Community mental health facility & $1(0.6)$ \\
\hline Other & $3(1.8)$ \\
\hline alncludes foreign language and international relations majors and minors. & $1(0.6)$ \\
\hline $\begin{array}{l}\text { bIncludes study abroad, language-based, globally focused research or clinical work, and } \\
\text { medical missions. }\end{array}$ & $6(3.6)$ \\
\hline $\begin{array}{l}\text { CIncludes work with impoverished or homeless communities, people living with HIV/AIDS, } \\
\text { and victims of violence. }\end{array}$ & \\
\hline
\end{tabular}

Participants were a median 6 years post-graduation at the time of the survey (range: 5-8 years). Fiftyeight of the 167 participants were still in training, including 22 residents, and 36 fellows (Table 1). Most participants $(52.9 \%)$ reported performing work or volunteer experiences with a global focus and onequarter $(22.2 \%)$ reported an experience working with a special population prior to attending medical school (Table 1). Seventy-eight participants (46.7\%) reporting completing a global elective during medical school.

Of 161 participants who provided data on the primary outcome ("working with underserved populations"), 31 reported practicing with a medically underserved population in the U.S., 121 reported clinical practice, research, teaching, or programmatic work with a global focus from the U.S. (including 111 who reported clinical practice with immigrant populations in the U.S.), and 4 reported practicing in a global setting. The percentage of participants who reported working with underserved populations was higher among those who had completed a work or volunteer experience with a global focus prior to medical school (82.5\% vs. $72.1 \%, p=0.1)$, or completed a global elective in medical school $(90.8 \%$ vs. $65.9 \%, p=0.0002)$ or residency $(90.0 \%$ vs. $71.4 \%, p=0.01)$ (Table 2 , second column). Alumni race and Latinx ethnicity, 
disadvantaged economic situation prior to medical school, and burden of student loan debt were comparable between participants. 
Table 2

Frequency of working with underserved populations among participants from medical school classes of 2011-2015, by selected characteristics $(n=161)$

\begin{tabular}{|c|c|c|c|}
\hline & $\begin{array}{l}\text { Works with } \\
\text { underserved } \\
\text { populations } \\
\text { n (\%) }\end{array}$ & $\begin{array}{l}\text { Does not work with } \\
\text { underserved } \\
\text { populations } \\
\text { n (\%) }\end{array}$ & $p^{b}$ \\
\hline \multicolumn{4}{|l|}{ Race } \\
\hline White & $96(78.7)$ & $26(21.3)$ & \multirow[t]{2}{*}{0.6} \\
\hline Non-white & $29(74.4)$ & $10(25.6)$ & \\
\hline \multicolumn{4}{|l|}{ Ethnicity } \\
\hline Latinx & $5(83.3)$ & $1(16.7)$ & \multirow[t]{2}{*}{1.0} \\
\hline Not Latinx & $120(77.4)$ & $35(22.6)$ & \\
\hline \multicolumn{4}{|l|}{ Race/Ethnicity } \\
\hline White, non-Latinx & 95 (77.7) & $27(22.1)$ & \multirow[t]{2}{*}{0.9} \\
\hline Non-white, including Latinx & $30(76.9)$ & $9(23.1)$ & \\
\hline \multicolumn{4}{|c|}{$\begin{array}{l}\text { Disadvantaged economically by self-report } \\
\text { (13 missing) }\end{array}$} \\
\hline Yes & $10(83.3)$ & $2(16.7)$ & \multirow[t]{2}{*}{1.0} \\
\hline No & 105 (77.2) & $31(22.8)$ & \\
\hline \multicolumn{4}{|c|}{$\begin{array}{l}\text { Amount of medical student loan debt ( } 7 \\
\text { missing) }\end{array}$} \\
\hline$\geq \$ 100,000$ & $64(78.1)$ & $18(21.9)$ & \multirow[t]{2}{*}{0.8} \\
\hline$<\$ 100,000$ & $55(76.4)$ & $17(23.6)$ & \\
\hline \multicolumn{4}{|c|}{ College major/minor had global focus } \\
\hline Yes & $19(90.5)$ & $2(9.5)$ & \multirow[t]{2}{*}{0.2} \\
\hline No & $106(75.7)$ & $34(24.3)$ & \\
\hline \multicolumn{4}{|c|}{$\begin{array}{l}\text { Completed work/volunteer experience with } \\
\text { global focus before medical school ( } 13 \\
\text { missing) }\end{array}$} \\
\hline Yes & $66(82.5)$ & $14(17.5)$ & \multirow[t]{2}{*}{0.1} \\
\hline No & $49(72.1)$ & $19(27.9)$ & \\
\hline
\end{tabular}




\begin{tabular}{|c|c|c|c|}
\hline & $\begin{array}{l}\text { Works with } \\
\text { underserved } \\
\text { populations } \\
\text { a } \\
\mathrm{n}(\%)\end{array}$ & $\begin{array}{l}\text { Does not work with } \\
\text { underserved } \\
\text { populations } \\
\mathrm{n}(\%)\end{array}$ & $p^{b}$ \\
\hline Yes & $29(85.3)$ & $5(14.7)$ & \multirow[t]{2}{*}{0.2} \\
\hline No & $86(75.4)$ & $28(24.6)$ & \\
\hline \multicolumn{4}{|c|}{ Completed a global elective in medical school } \\
\hline Yes & $69(90.8)$ & $7(9.2)$ & \multirow[t]{2}{*}{0.0002} \\
\hline No & $56(65.9)$ & $29(34.1)$ & \\
\hline \multicolumn{4}{|c|}{$\begin{array}{l}\text { Completed a global elective in residency ( } 6 \\
\text { missing) }\end{array}$} \\
\hline Yes & $45(90.0)$ & $5(10.0)$ & \multirow[t]{2}{*}{0.01} \\
\hline No & $75(71.4)$ & $30(28.6)$ & \\
\hline \multicolumn{4}{|c|}{$\begin{array}{l}\text { ancludes participants who reported working in a global setting, in } \\
\text { globally focused activities, or with underserved populations in the } \\
\text { United States }\end{array}$} \\
\hline \multicolumn{4}{|c|}{${ }^{\mathrm{b}} \mathrm{p}$-values for variables with cell sizes $<5$ were estimated using } \\
\hline
\end{tabular}

Table 3

Multivariable correlates of working with underserved populations among participants from medical school classes 2011-2015 $(n=161)$

\section{Covariate}

\section{Adjusted Prevalence Ratio ${ }^{\text {a }}$ (95\% Confidence Interval)}

Full sample ( $\mathrm{n}$ Sample excluding residents and $=161)$ fellows $(n=106)$

Completed a global elective in medical school

$1.38(1.16$

Asian, Black, Indigenous, or Latinx vs. White non-Latinx

$0.98(0.84$, 1.15)

$1.30(1.04,1.64)$

aPrevalence ratio adjusted for all other variables in the table.

Most participants reported that they consider the global experience improved their cultural competency (72.4\%) and understanding of public health topics and methods (71.1\%) (Table 4). Only $12 \%$ reported that the experienced improved their research skills, while substantial proportions reported it improved their language skills, as well as improved clinical and diagnostic skills in low-technology settings (Table 4). 
When asked to describe how the experience influenced their ability to get the job they wanted $(n=53), 29$ participants $(54.7 \%)$ reported that the experience was a positive influence:

Table 4

Self-reported benefits of global electives among participants from medical school classes of 2011-2015 $(n=78)$

\begin{tabular}{ll} 
Skill & $\begin{array}{l}\text { Substantia } \\
(\%)\end{array}$ \\
\hline Improved clinical skills (3 missing) & $24(32.0)$ \\
\hline $\begin{array}{l}\text { Improved diagnostic skills in the absence of technology (2 } \\
\text { missing) }\end{array}$ & $30(35.9)$ \\
\hline Improved cultural competency (2 missing) & $55(72.4)$ \\
\hline Improved public health understanding (2 missing) & $54(71.1)$ \\
\hline Improved research skills (3 missing) & $9(12.0)$ \\
\hline Improved language skills (2 missing) & $31(40.8)$
\end{tabular}

"Due to my immersion experience in Guatemala I was able to see Spanish speaking patients throughout residency and now in my career I speak Spanish daily. It has made me a marketable provider to be bilingual and I have a cultural competency regarding patients from Central America that I would not have had with simple language training in the U.S." (Participant reported their practice was in a federal health professional shortage area, outpatient setting with immigrant and Medicaid populations in the U.S

Twenty participants (37.7\%) reported the experience had no influence on being hired in their desired job, whereas no participant identified the experience as negative. Four participants (7.5\%) indicated the experience seemed to have strengthened their candidacy for residency:

"These experiences provided further training in caring for underserved populations and informed my care of immigrant populations. The experiences were good to include on my CV [and] improved physican exam skills and diagnostic skills without technology" (Participant reported practicing in outpatient settings with immigrant and Medicaid populations in the U.S.)

\section{Discussion}

In this analysis of survey and medical school application data, we found that participants who reporting completing a global elective during medical school were $38 \%$ more likely to report currently working with underserved populations. However, completion of a work or volunteer experience with global focus before entering medical school was not strongly associated with current work with underserved populations. Medical school graduates who participated in electives in global settings also reported several benefits of these experiences, including building cultural competency and language skills, having a better understanding of public health, and improved clinical and diagnostic skills in the absence of technology. 
This association between completing a global elective as medical students or residents and choice to work with underserved populations remained statistically significant and meaningful in magnitude after adjusting for student race and ethnicity. We performed a descriptive analysis excluding those still in clinical training programs, and found that practicing clinicians who completed global health electives as residents were highly likely to have done so in medical school as well. This suggests that medical school electives might indeed drive interest in global health careers. Our findings are consistent with prior studies that found a similar association between a medical school global elective experience and an intention of working or living in an underserved setting. (Jeffrey, J., et al., 2011; O'Connell, T. F. et al., 2018). However, these studies were limited to the "intent" to practice rather than actual practice outcome. Our study surveyed medical school alumni four to eight years after graduation and we ascertained actual practice outcome. Omoren, et al. surveyed physicians and found that as compared to controls, physicians who had performed a two-month elective in Kenya during medical school were more likely to pursue primary care careers with underserved populations (2015).

In our analysis, to better understand the myriad factors that may contribute to eventual career choice, we included student characteristics prior to entering medical school by incorporating AMCAS data. While our results did not identify statistically significant relationships between these characteristics prior to medical school, it is possible that they influence choices of medical school experiences to a lesser degree (Puddey, I.B., et al., 2015). Qualitative research may help inform which experiences, or which qualities of the experiences, were most instrumental in directing eventual career trajectory.

When asked about their perceptions of their global health experiences and their influence in getting the jobs they wanted, participants noted several benefits, including improved cultural competency and clinical and diagnostic skills despite technological limitations. None of the participants reported the program had any negative impact on their career choices, suggesting that these experiences offer definitive benefits to participants, even if they are not necessarily motivated to pursue global health careers.

Asian, Black, Indigenous, and Latinx race and ethnicity was potentially associated with both completing global health electives and working with underserved populations. A recent study of the career intentions of over 40,000 medical school graduates found that underrepresented racial and ethnic groups were nearly twice as likely as white students to report working with underserved populations (Garcia, A. N. et al., 2018). However, our study sample was predominantly white and non-Latinx. While race and ethnicity were not associated with the outcome in bivariate analysis, the small number of Asian, Black, and Indigenous ( $n=39)$ and Latinx $(n=6)$ participants prevents us from making definitive conclusions about the likelihood of these individuals engaging in work with underserved populations. Future studies may need to oversample participants from Black, Asian and Indigenous and Latinx groups to better understand predictors of their engaging in work with underserved populations, and qualitative research in smaller samples can elucidate motivations for choosing this career path or not. 
There were very few respondents that reported conducting global health practice in an international setting despite completing a global elective in medical school, to be able to draw any association $(n=4)$. That being said, most respondents, $(n=121)$, reported clinical practice, research, teaching, or programmatic work with a global focus within the U.S. Further research can supplement these data to better understand factors identifying global health engagement. This study also has implications for global health education in the medical school setting, including a better understanding of the barriers to global health careers and how we can help trainees surmount these barriers.

A limitation of this study is that it was conducted among a moderately-sized sample of graduates from a single medical school, and the findings might not be applicable to all medical school contexts. We attempted to maximize the response rate by extending the survey deadline and increasing the incentive amount; however, we only achieved a final response rate of $21.7 \%$. A post-hoc comparison showed that respondents and non-respondents were comparable with respect to age, though women were more likely to respond than men (data not shown). It is unclear if non-respondents are more or less likely to have taken global health electives or currently work with underserved populations, and whether their inclusion would have affected our conclusions. Furthermore, since most participants reported working with immigrant populations in the United States (three-quarters of these reporting doing so between $1-25 \%$ of their working hours) it is possible that alumni currently involved in work with underserved populations were more motivated to respond to the survey.

\section{Conclusion}

In a sample of graduates from a large, public medical school on the east coast, having completed a global health elective during medical school was associated with a $38 \%$ increase in pursuing a career working with underserved populations, while few students overall pursued full-time clinical careers in global settings. Participants who participated in these electives reported multiple benefits, namely improving cultural competency and improving public health knowledge. Opportunities to grow and strengthen global health opportunities for medical students may increase the likelihood that they pursue careers dedicated to underserved populations in the United States and abroad. Medical school administrators and educators can use these data to guide curriculum planning around global electives and may want to focus learning objectives on strengthening skills that could be used in clinical practice both outside and inside the United States.

\section{Declarations}

\section{- Ethics approval and consent to participate}

- The study was reviewed by the Office of Human Research Ethics and approved by the Institutional Review Board of the University of North Carolina at Chapel Hill (study \#18-2374) and was determined to be exempt from further review. 


\section{- Consent for publication}

- Not applicable; no identifying individual data was collected.

- As per required by the IRB of UNC Chapel Hill, consent was obtained from each participant upon informing them of the study's purpose and aim.

\section{- Availability of data and materials}

- The datasets generated and/or analyzed during the current study are not publicly available due to the use of AMCAS data which requires institutional permission but additional specific tables and data are available from the corresponding author on reasonable request.

\section{- Competing interests}

- The authors declare that they have no competing interests.

\section{- Funding}

- S.B,-D. is supported by a mid-career research development award from the National Institutes of Health (K24Al141744).

\section{- Authors' contributions}

- E.S primarily oversaw the study and wrote the first draft of the manuscript. N.A.V analyzed the study data and interpreted the results. D.E.P provided guidance on the use of data sources and interpreted the study results. SBD, JGM and MCC conceived of the study and contributed subject-matter expertise and interpretation of results. All authors contributed to the development of the study design and analysis plan, and all authors have read, revised and approved the final manuscript.

\section{- Acknowledgements}

- We thank Michel Branch, BA, MPH, Application Analyst Advanced, for his expertise and assistance with the AMCAS data pertinent for this study.

\section{References}

Carlough MC, Becker-Dreps S, Hawes S, Hodges, Martin I, Denniston C. A medical school's approach to meeting the challenges of interdisciplinary global health education for resident physicians. Education for Health. 2016 May 1;29(2):113.

Garcia AN, Kuo T, Arangua L, Pérez-Stable EJ. Factors associated with medical school graduates' intention to work with underserved populations: policy implications for advancing workforce diversity. Academic medicine: journal of the Association of American Medical Colleges. 2018 Jan;93(1):82. 
Greer PJ Jr, Brown DR, Brewster LG, Lage OG, Esposito KF, Whisenant EB, Anderson FW, Castellanos NK, Stefano TA, Rock JA. Socially accountable medical education: an innovative approach at Florida International University Herbert Wertheim College of Medicine. Academic Medicine. 2018 Jan;93(1):60.

Jeffrey J, Dumont RA, Kim GY, Kuo T. Effects of international health electives on medical student learning.

and career choice. Fam Med. 2011 Jan 1;43(1):21 - 8.

Jogerst K, Callender B, Adams V, Evert J, Fields E, Hall T, Olsen J, Rowthorn V, Rudy S, Shen J, Simon L. Identifying interprofessional global health competencies for 21 st-century health professionals. Annals of Global Health. 2015 Mar 1;81(2):239 - 47.

Kasper J, Mulye A, Doobay-Persaud A, Seymour B, Nelson BD. Perspectives and Solutions from Clinical Trainees and Mentors Regarding Ethical Challenges During Global Health Experiences. Annals of global health. 2020;86(1).

Law IR, Walters L. The influence of international medical electives on career preference for primary care and rural practice. BMC medical education. 2015 Dec 1;15(1):202.

Litzelman DK, Gardner A, Einterz RM, Owiti P, Wambui C, Huskins JC, Schmitt-Wendholt KM, Stone GS, Ayuo PO, Inui TS, Umoren RA. On becoming a global citizen: transformative learning through global health experiences. Annals of global health. 2017 May 1;83(3-4):596-604.

Lu PM, Park EE, Rabin TL, Schwartz JI, Shearer LS, Siegler EL, Peck RN. Impact of global health electives on us medical residents: a systematic review. Annals of global health. 2018;84(4):692.

Mullan F, Chen C, Petterson S, Kolsky G, Spagnola M. The social mission of medical education: ranking the schools. Annals of Internal Medicine. 2010 Jun 15;152(12):804-11.

O'Connell TF, Ham SA, Hart TG, Curlin FA, Yoon JD. A national longitudinal survey of medical students' intentions to practice among the underserved. Academic Medicine. 2018 Jan 1;93(1):90 - 7.

Pathman DE, Konrad TR, King TS, Spaulding C Jr. DH. Medical training debt and service commitments: the rural consequences. The Journal of Rural Health. 2000 Jun;16(3):264-72.

Puddey IB, Mercer A, Playford DE, Riley GJ. Medical student selection criteria and socio-demographic factors as predictors of ultimately working rurally after graduation. BMC Medical Education. 2015 Dec $1 ; 15(1): 74$.

Steeb DR, Dascanio SA, Kiser SN. Connecting Rural and Global Health Education for Workforce Development. The American Journal of Tropical Medicine and Hygiene. 2019 Sep 4;101(3):479-81. 
Umoren RA, Gardner A, Stone GS, Helphinstine J, Machogu EP, Huskins JC, Johnson CS, Ayuo PO, Mining S, Litzelman DK. Career choices and global health engagement: 24-year follow-up of US participants in the Indiana University-Moi University elective. In HealthCare 2015 Dec 1 (Vol. 3, No. 4, pp. 185-189). Elsevier. 